\title{
CRISPR-Cas: Removing Boundaries of the Nature
}

\author{
Nicat Cebrailoglu' ${ }^{1}$, Ali Burak Yildiz' ${ }^{\mathbb{D}}$, Ozlem Akkaya' ${ }^{1}$, Yelda Ozden Ciftci ${ }^{1}$ (D) \\ ${ }^{1}$ Gebze Technical University, Department of Molecular Biology and Genetics, Kocaeli, Turkey
}

ORCID IDs of the authors: N.C. 0000-0002-2770-5049; A.B.Y. 0000-0002-9982-7109; O.A. 0000-0003-0473-1417;

Y.O.C. 0000-0002-9799-3648

Please cite this article as: Cebrailoglu N, Yildiz AB, Akkaya O, Ozden Ciftci Y. CRISPR-Cas: Removing boundaries of the nature. Eur J Biol 2019; 78(2): 157-164. DOI: 10.26650/EurJBiol.2019.0024

\begin{abstract}
The CRISPR-Cas 9 system, which is known as a natural way of bacteria to defend against phage infection and plasmid transfer, has been re-purposed as a RNA-guided DNA targeting strategy for genome editing. Together with the advances gained in DNA sequencing technology, this platform opened a new era in molecular biology since its recognition was specified by 20 -nt single-guide RNA which made technique easier, efficient and simple for application in any organism. Thus, many studies have discussed and performed the applications of CRISPR-Cas systems on different organisms for genome editing. Moreover, targeted gene regulations, epigenetic modulation, chromatin imaging and manipulation could also be applied with this system. Besides all its potential promising aspects, this tool might have some side effects like off-target mutations. In addition, unexpected results have also been reported after some gene editing applications. Thus, this review provides a brief history of gene editing tools together with the overview of the latest applications, regulations and ethical/structural aspects of the CRISPR Cas system.
\end{abstract}

Keywords: Gene editing, Gene therapy, Meganucleases, TALEN, ZFN, New breeding technologies

\section{INTRODUCTION}

Investigations on natural protection ways of bacteria against phages resulted in tremendeous turning points in recombinant DNA technology. Starting with the discovery of restriction enzymes in the late 1970s that enabled scientists to manipulate DNA in test tubes (1), it allowed many opportunities of genetic manipulations in many organisms including bacteria, plants, animals and even humans. The key developments on the precise alteration of DNA in living eukaryotic cells, which is termed as "gene editing" (GE), started with Rothstein's report in 1983 on yeast cells. Afterwards, Smithies and co-workers (1985) followed by Capecchi (2) demostrated that it was possible to incorporate an exogenous copy of DNA into the mammalian cells genome through homologous recombination (HR). Although these studies resulted in the characterization of functional roles of many genes in model organisms, they have the following limitations, such as i) the rate of spontaneous integration was too low (1 in $10^{3-}$ $10^{9}$ cells, Capecchi, 1989), ii) type and the state of the cell affected the integration rate, iii) the possibility of random integration of exogenous copy to undesired site was similar or even higher than the target site (3).

To overcome these obstacles, scientists started to use different approaches among which the construction of a double-strand break (DSB) at a target site provided the best alternative for the elevation of targeted gene integration frequency. Thus, natural rare cutting meganucleases (i.e., I-Scel) and then re-engineered ones were utilized to achieve targeted DSBs. Even though these attempts resulted in some improvements, these enzymes had several disadvantages listed in Table 1. Afterwards, zing fingers, that are zinc ionregulated small proteins that recognize and bind a $3 \mathrm{bp}$ DNA sequence (4), were fused with the DNA cleavage domain of the Fok I endonuclease which is isolated from Flavobacterium okeanokoites to create a programmable 
nucleases (5). Zinc finger nucleases (ZFN) then increased the capability to edit genomes at the targeted sites enabling the usage of this technique for therapeutic applications (6). Likewise, Fok I DNA cleavage domain is also combined with TALE modules in order to be utilized as an effective programmable nuclease (TALEN, transcription activator-like effector nucleases) (7). In contrast to ZFN that recognize a $3 \mathrm{bp}$, TALE proteins from Xanthomonas bacteria can recognize one single base. By using these nucleases, a DSB can be introduced in any site of the genome with known recognition sites of the DNA-binding domains. However, it should also be noted that TALEN nuclease sites require $T$ before the $5^{\prime}$-end of the target sequence which could limit its application.

Although "Nature Methods" announced ZFN and TALEN as the method of the year for precise GE tools (https://www.nature. com/articles/nmeth.1852.pdf), their disadvantages indicated in Table 1 made researchers seek alternative approaches such as the Clustered Regularly Interspaced Short Palindromic Repeats (CRISPR)-associated protein 9 (Cas9) system. CRISPR-Cas9 system, which is known as a natural way of bacteria to defend against phage infection and plasmid transfer, has been repurposed as a RNA-guided DNA targeting strategy for genome editing and opened a new era in molecular biology since its recognition was specified by 20 -nt single-guide RNA (sgRNA) (8).
This recent platform not only mimics the natural trans-activating CRISPR RNA (tracrRNA) and CRISPR RNA (crRNA) structure, but also in contrast to ZFN and TALEN, there is no need for tedious protein engineering of DNA-recognition domains for each target site which make the design easy, simple to use and efficient (9).

\section{CRISPR-Cas: STRUCTURE AND FUNCTION}

CRISPR-Cas systems are based on two molecules, guide RNA (gRNA) and Cas protein which are responsible of binding on a specific target at the genome and cutting the target point, respectively. The most applied and discussed one is the CRISPRCas9 system, which causes a DSB at the specific target area on the genome and silencing of the gene. This DSB might be repaired by either homology directed repair (HDR) or nonhomologous end joining (NHEJ) systems. During the repairing of the gene via these two different types of systems, some indels might occur. Except triple insertion or deletions, other nucleotide changes cause frameshift mutations on the gene. Even though Streptococcus pyogenes (SpCas9) is the most used and studied one, there are more types of Cas proteins which are parts of immune metabolisms of archaea and bacteria. In order to function properly, those proteins require some specific short nucleotide sequences near the target area, which is called the protospacer adjacent motif (PAM) that may vary between different Cas proteins (10).

Table 1: The advantages and disadvantages of gene editing tools.

\begin{tabular}{|c|c|c|}
\hline Gene Editing Techniques & Advantages & Disadvantages \\
\hline Meganucleases & $\begin{array}{l}\text {-its ability to recognize long stretches of } \\
\text { 14-40 bp DNA increased previously the } \\
\text { genome editing efficiency }\end{array}$ & $\begin{array}{l}\text {-As each enzyme has a unique } \\
\text { recognition sequence, the possibility of } \\
\text { finding a right meganuclease to make a } \\
\text { precious target was low. } \\
\text {-Since the majority of induced DSBs are } \\
\text { repaired through NHEJ, this mechanism } \\
\text { may randomly insert or delete DNA } \\
\text { pieces at the break site (100) }\end{array}$ \\
\hline ZFNs & $\begin{array}{l}\text {-increased targeted homologous } \\
\text { recombination in model organisms and } \\
\text { human cells. }\end{array}$ & $\begin{array}{l}\text {-DNA recognition is specified by protein } \\
\text {-Require tedious protein engineering of } \\
\text { DNA-recognition domains for each target } \\
\text { site }\end{array}$ \\
\hline TALENs & $\begin{array}{l}\text {-The recognization ability of one base } \\
\text { instead of } 3 \text { bp of TALE proteins together } \\
\text { with fusion of the Fok I DNA cleavage } \\
\text { domain served it as an efficient gene } \\
\text { editing tool. }\end{array}$ & $\begin{array}{l}\text {-DNA recognition is specified by protein } \\
\text {-Require tedious protein engineering of } \\
\text { DNA-recognition domains for each target } \\
\text { site }\end{array}$ \\
\hline \multirow[t]{2}{*}{ CRIPSR/CAS9 } & $\begin{array}{l}\text {-Ease of design, simplicity in use and } \\
\text { highly efficient }\end{array}$ & -Off-target and unexpected mutations \\
\hline & $\begin{array}{l}\text {-Can be used not only for genome } \\
\text { editing, but also transcriptional } \\
\text { perturbation, epigenetic, modulation and } \\
\text { genome imaging }\end{array}$ & \\
\hline
\end{tabular}


Newly discovered CasX protein has a great potential of human GE since it has a small size and the transformation of this protein to human cells is much easier than other Cas proteins. In addition to that, unlike some Cas 9 proteins, CasX proteins are not found in bacteria which live in the human body and CasX proteins do not have any common ancestors with Cas9 proteins. Because of this reason, human immune systems are not capable of showing a strong response against CasX proteins (11). Similar to CasX, Cas14 also has a small size and does not require PAM sequence to generate single strand DNA break (12). Another Cas protein is Cas12a, also known as Cpf1, causes sticky DSB which makes easier the gene insertion into target loci (13).

Depending on the purpose, the Cas protein might be used single or as a fusion protein. For instance, Cas9 protein with an inactivated catalytic side (dCas9) is fused with cytidine deaminase to convert cytidines to uridines without causing any DSB on the target side (14). This method might be used for opposite change, uridines to cytidines with adenosine deaminase (15). CRISPR-Cas system is also utilized for generating epigenetic changes. There are three types of epigenetic changes generated by the CRISPR-Cas system: i) single or multiple gRNAs can manipulate dCas9 fused to a VP64 transcriptional activation domain to enhance the expression of endogenous human genes (16), ii) dCas9-KRAB fusions block the binding or progressing of DNA polymerase, resulting in repression of transcription (17), iii) targeted DNA methylation editing by using dCas9-TET1 catalytic domain fusions (18).

Since DNA editing causes permanent changes on the genome, off-target brings some huge risks for the future of the organism. This situation gives researchers a reason to use the CRISPR-Cas system on RNA editing to prevent these risks, as these types of changes stay at the transcriptional level. For RNA editing, researchers use two types of Cas proteins, Cas13a and Cas13b. Cas13a is used for mRNA degradation, on the other hand dCas13b-ADAR fusion is used for base editing on mRNA (19).

There are several methods for delivering components of the CRISPR-Cas system to an organism. These methods are classified as physical (electroporation) (20), viral (adenovirus, lentivirus, tobacco rattle virus) (21-23) and non-viral methods (lipid nano particles, agrobacterium) (24, 25). After delivery, for the screening of the changes on cell or organisms, several methods are used. Screening of large-scale mutation requires sequencing or determination of the DNA band size with electrophoresis (26). For screening of small-scale mutation T7 endonuclease assay or restriction enzyme assay might be used $(27,28)$.

As discussed before, CRISPR is a mechanism of bacterial immune system against phages. On the other hand, phages also developed inhibitor proteins against this bacterial mechanism. Those proteins are called anti-CRISPR proteins, which allow us the control application of CRISPR and make clinical trials safer (29).

\section{RECENT APPLICATIONS}

In order to use this technology as a gene therapy tool, CRISPR needs to be delivered to the right cells in the human body. There are two different applications: in vivo and in vitro. Genome editing via cas- 9 in vivo has been used to correct alleles associated with genetic diseases in animal models. In order to lead to cataract-free progeny, CRYGC gene, causing dominantnegative cataract, mutated by injecting Cas9 mRNA into the zygote of the mouse heterozygote and a sgRNA targeting only in the mutant allele (30). Furthermore, in case of this technique was applied to a $m d x$ mouse which had a mutation in the gene encoding dystrophin, phenotypic correction was observed between $2 \%$ to $\% 100$ percent when Cas9, sgRNA and donor template were injected into mouse zygotes (31). All of these studies showed promising advances in the treatment of genetic diseases.

Streptococcus pyogenes Cas9 (SpCas9) promises great potential for curing hereditary disorders including muscle dystrophy, HIV, vision disorders and many others. However, for all these applications to be possible, the dose and timing of SpCas9 activity should be adjusted to reduce the effects of off-targets. If SpCas9 activity can be controlled in these aspects; editing of DNA in model organisms can be successfully achieved. As an example, gene drives in genetically altered mosquitoes can prevent the spread of malaria and similar diseases transmitted by mosquitoes. The demand for the control of SpCas9 acitivity has raised a requirement for anti-CRISPR molecules. Although the anti-CRISPR proteins target SpCas9 are large and cannot pass through the cells, which can break down by proteases and cause the formation of an adverse immune reactions in the body. Whereas small molecule inhibitors are proteolytically stable and generally do not produce an immune response since they can diffuse through the cells. Future studies are needed to identify the mechanisms of action of the inhibitors on SpCas9: gRNA binding domains (32).

Although many studies have focused on the Cas9 protein so far; in recent years, the CRISPR-Cpf1 protein, also known as Cas12a, has been shown to be more effective than Cas9. As a matter of fact, companies like Mammoth Biosciences have already started using Cas12a technology. Patents containing the Cas12a-RNA complex are supported by the Berkeley and the Broad Institute. Recently CasX, which was originally discovered in Jennifer Doudna's laboratory in 2017, is much smaller than other Cas proteins and has the ability to shade both Cas9 and Cas12a. Since it sources are from bacteria that are not found in humans, the human immune system is more likely to accept it than Cas9 $(32,33)$. Differently, the newly developed Cas13-based SHERLOCK, which targets RNA, allows us to diagnose multiple diseases with one test and gives us a hundred times more sensitive results. Following the bonding of Cas13 with the viral genome, Cas13 starts to cut free specific RNAs, and these RNA cuttings trigger the formation of signals. 
Currently, CRISPR gene-editing technology has been started to be used for human clinical trials: $\beta$-thalassemia [Vertex Pharmaceutical/CRISPR Therapeutics], Cancer (melanoma, sarcoma, myeloma) [U Penn/Parker Institute] and HIV [Affiliated Hospital to Academy of Military Medical Sciences]. The earlier studies led by Feng Zhang (MIT) and George Church (Harvard University) showed that the CRISPR system could be used to edit eukaryotic mammalian cells, including human cells. Later, a lot of researches were performed in this field. In November 2018 the Chinese researcher He Jiankui made the world's first genetically edited babies. He used CRISPR to mutate the gene called CCR5. Disabling this gene would prevent the HIV virus from entering and destroying Helper T cells. If everything had been gone as planned, children with an immune response to AIDS would have been born. However, it was shown that the growing CRISPR babies may face earlier deaths (average of 1.9 years) (34) a the genetic mutation that protects against HIV causes the babies to have a shorter life span.

Moreover, CRISPRi in which dCas9 is fused to a transcriptional repressor domain [Kruppel associated box (KRAB)] for repression of transcription and CRISPRa in which dCas9 is fused to a sequence (SunTag) containing multiple copies of the activator recruitment domain of the general control protein (GCN4) to activate transcription are also used to elucidate the non-coding genome (35-37). Genome editing by this method allows for efficient disorder of regulatory elements without causing DNA mutations. To sum up, dCas9-based methods enable to clarify the roles of regulatory sequences within the natural genomic structure and can elucidate long nonfacilitating RNAs that can be altered by indels generated with Cas9 nucleases (38).

The chromatin structure modulates the genome. However, elucidation of the basis of this modification depends on a limited number of methods used to study chromatin-protein interactions. To identify proteins that interact with a specific genome locus; the chromatin may be precipitated with an antibody against a dCas9-tag fusion protein expressed together with gRNA targeting the desired DNA sequence, which is called 'engineered DNA-binding molecule-mediated chromatin immunoprecipitation' (enChIP). Later on, locus-associated proteins can be identified by mass spectrometry (39). enChIP is used in living cells for biochemical analysis of transcription and epigenetic regulation (40).

CRISPR-based tools can create a new guide RNA, enabling easier genome-wide screening. Many researchers have reported that screening with this method is more specific and more efficient than RNAi, and yields more robust and trustable results (41). In these experiments, sgRNA libraries and Cas 9 cells are introduced into the cell, and selection of the treated cells was conducted according to those showing the targeted phenotypic result (42). Such screenings have been used to identify genes that are involved in cancer progression (43), drug resistance (44), immune response (45) susceptibility to bacterial toxins (46) and the emergence of other biomedically important phenotypes.
The ability to screen multiple loci in the human genome at the same time by performing a single experiment via Cas9 (47) enables the identification of complex cell signaling pathways, gene functions, drug targets for therapeutic purposes, and predicting drug side effects.

\section{PLANT CRISPR EDITING}

In plant biotechnology, CRISPR is used for both improving and gaining features on plants, such as yield and quality (48-52), herbicide tolerance $(53,54)$, biotic and abiotic tolerance $(26$, 55-57). Along with those, CRISPR is also used for functional genomic $(58,59)$ studies. High mutation frequency of CRISPR is especially important for creating homozygote mutant lines on polyploid plants such as wheat, potato and strawberry. In regards to potato, researchers established a single base change in the ALS gene of the tetraploid plants by using Cas9-Cytidine deaminase fusion, and made the plant resistant to the chlorsulfuron herbicide. This mutation prevents the acetolactate synthase enzyme from inhibition by chlorsulfuron binding (60). Furthermore, CRISPR has made it easy to target multiple genes in a single organism. For instance, researchers mutated different genes in cultivated tomatoes with a single CRISPR application to ensure recovery of stress tolerance since tomato has lost its tolerance to stress due to domestication for a long time. As a result, tomatoes with a bigger fruit size, number and nutritional value were obtained (61). In another study, the Fad 2.1 gene, responsible for the conversion of oleic acid to less stable linoleic acid, was knocked-out by Calytx Inc. to increase the oleic acid content of the soybean and ultimately the shelf life of the soybean oil. This first commercial GE plant, which was developed for the first time with TALEN, was later achieved by the CRISPR technique (62).

\section{BACTERIAL GENOME EDITING WITH CRISPR}

Since there are other effective methods for genome editing in microorganisms such as HR; few studies have been reported on the development of CRISPR-Cas genome editing in various bacteria (i.e., E. coli, Cyanobacteria, Streptomyces, Riemerella anatipestifer, Clostridium, Corynebacterium, Bacillus, Salmonella, Pseudomonas putida, Lactobacillus casei) (63-72). Identification of strains (73), detection of natural or engineered immunity against mobile genetic elements $(74,75)$, manipulation of microbial consortium (76), and programmable transcriptional regulation (77) are some issues that have been tried to be solved using CRISPR. Moreover, patent studies in this field focused on the growth of microorganisms, preventing antibiotic resistance, biofuel production and enhanced synthesis of desired metabolites (78). The development of this method will enable efficient screening and selection of targeted mutations in microorganisms.

\section{ETHICS AND SAFETY REGULATIONS}

Since the first publication in 2012 (79) that reported CRISPR-Cas9 usage for genome editing; this method has been described by different names such as "revolutionary", a "groundbreaking" and 
Table 2: Regulatory decisions of different countries for GE crops.

\begin{tabular}{|c|c|c|}
\hline Countries & Regulation Decisions & References \\
\hline Australia & $\begin{array}{l}\text { Most genome editing techniques will be explicitly } \\
\text { regulated. But the technique known as SDN-1 [generation of } \\
\text { small deletions or insertions (indels) at a precisely defined } \\
\text { location] will be excluded* / WTO Statement }\end{array}$ & $92 ; 93$ \\
\hline Argentina, Brazil, Canada, Chile, Colombia, USA & Non-transgenic GE crops are not GMO / WTO Statement & $94 ; 93$ \\
\hline $\begin{array}{l}\text { Dominican Republic, Guatemala, Honduras, } \\
\text { Jordan, Paraguay, Uruguay, Vietnam, Economic } \\
\text { Community of West African States (ECOWAS) }\end{array}$ & WTO Statement & 93 \\
\hline Japan & $\begin{array}{l}\text { There is little difference between traditional breeding } \\
\text { methods and gene editing in terms of safety (Japan } \\
\text { Governmental Advisory Committee) }\end{array}$ & 96 \\
\hline Russia & $\begin{array}{l}\text { GE technologies as equivalent to conventional breeding } \\
\text { methods. }\end{array}$ & 95 \\
\hline The European Court of Justice(ECJ) & Using recombinant nucleases cause GMO & 97 \\
\hline Belgium, Sweden, UK & $\begin{array}{l}\text { Calling to update EU GMO laws / Gave permission for field } \\
\text { trials before ECJ ruling }\end{array}$ & $99 ; 98$ \\
\hline $\begin{array}{l}\text { Cyprus, Estonia, Finland, France, Germany, } \\
\text { Greece, Netherlands, Italy, Portugal, Slovenia, } \\
\text { Spain }\end{array}$ & Calling to update EU GMO laws & 99 \\
\hline
\end{tabular}

"game changer", since it provided the opportunity of crossing species boundaries. Naturally, this facility seemed to be very promising at first glance for many researchers.

Clinical trials using CRISPR system for efficient genome editing of various mammalian cells have already started and give promise to the treatment of some major diseases (80-83). In fact, these clinical applications also highlighted the presence of certain risks. Ihry et al. (84) revealed that DSBs generated by Cas 9 could be toxic, and it created an obstacle for high genome-editing efficiency of CRISPR/Cas9 in human pluripotent stem cells. This study implied that using CRISPR in human cell lines increased the risk of cancer. Moreover, unexpected mutations resulting from CRISPR editing are another issue that needs improvement (85). Since these mutations can cause various genetic disorders or cancer, some social and ethical doubts about this genome engineering tool have appeared. Editing the unborn child to have the desired eyes or hair color (86), building an army with genetically edited soldiers (87) could be a few of the future applications of this unlimited technology. Despite all these possible risks and ethical considerations, the US and China are the countries that have allowed researchers to apply CRISPR editing on human CAR-T cells $(88,89)$. In addition to that, as it stated above, an illegal experiment was reported in China to make HIV resistant babies (90). However, it was later showed that HIV-resistant babies with CCR5 mutations were also sensitive to dangerous flu and West Nile Virus (91). All those present studies suggest that even though CRISPR is a very powerful technique, it is not always the first option in curing diseases.

Likewise, all these ethical and social aspects should also be discussed for gene-editing applications in agriculture. Since CRISPR provides gene editing without any DNA integration, in many countries, engineered plants using this technique have been accepted as a non-transgenic product that is allowed to enter the market freely without the need for regulation (92-97). Only the European Union decided that edited crops should be considered as GMOs (Table 2). However, in some European countries, field trials of altered plants using this approach are still ongoing. It is also expected that after "Brexit" the UK might remove the regulations for CRISPR-edited crops. Recently, 14 European Union (EU) countries have already made a call for updating the laws of GMOs according to New Plant Breeding Technologies $(98,99)$.

\section{CONCLUSIONS}

Although CRISPR-Cas system offers tremendious oppurtunities for clinical and biotechnological applications, it might cause some unexpected results which reveals that the technique needs to be improved and further tested. Besides, ethical issues and regulatory aspects should also be discussed in scientific consortia to have a common decision on GE applications prior to large-scale clinical and field applications. 
Peer-review: Externally peer-reviewed.

Author Contributions: Conception/Design of study: Y.A.C., Ö.A., N.C.; Data Acquisition: Y.A.C., Ö.A., N.C., A.B.Y.; Data Analysis/Interpretation: Y.A.C., Ö.A., N.C.; Final Approval and Accountability: Y.A.C., Ö.A., N.C., A.B.Y.; Drafting Manuscript: Y.A.C., Ö.A., N.C., A.B.Y..; Critical Revision of Manuscript: Y.A.C., Ö.A., N.C.; Supervision: Y.A.C.

Conflict of Interest: The authors declare that they have no conflicts of interest.

Financial Disclosure: There are no funders to report for this submission

\section{REFERENCES}

1. Adli M. The CRISPR tool kit for genome editing and beyond. Nat Commun 2018; 9(1): 1911.

2. Capecchi MR. Altering the genome by homologous recombination. Sci 1989; 244(4910): 1288-92.

3. Lin FL, Sperle $K$, Sternberg N. Recombination in mouse $L$ cells between DNA introduced into cells and homologous chromosomal sequences. Proc Natl Acad Sci USA 1985; 82: 1391-95.

4. Klug A, Rhodes D. 'Zinc fingers': a novel protein motif for nucleic acid recognition. Trends Biochem Sci 1987; 12: 464-69.

5. Kim YG, Cha J, Chandrasegaran S. Hybrid restriction enzymes: zinc finger fusions to Fok I cleavage domain. PNAS 1996; 93(3): 115660.

6. Urnov FD, Miller JC, Lee YL, Beausejour CM, Rock JM, Augustus S, et al. Highly efficient endogenous human gene correction using designed zinc-finger nucleases. Nature 2005; 435(7042): 646.

7. Christian M, Cermak T, Doyle EL, Schmidt C, Zhang F, Hummel A, Targeting DNA double-strand breaks with TAL effector nucleases. Genetics 2010; 186(2): 757-761.

8. Doudna JA, Charpentier E, The new frontier of genome engineering with CRISPR-Cas9. Sci 2014; 346(6213): 1258096.

9. Hsu PD, Lander ES, Zhang F. Development and applications of CRISPR-Cas9 for genome engineering. Cell 2014; 157(6), 1262-78.

10. Leenay RT, Maksimchuk KR, Slotkowski RA, Agrawal RN, Gomaa $A A$, Briner $A E$, Barrangou $R$, Beisel $C L$. Identifying and visualizing functional PAM diversity across CRISPR-Cas systems. Mol Cell 2016, 62(1): 137-47.

11. Liu JJ, Orlova N, Oakes BL, Ma E, Spinner HB, Baney KL, Al-Shayeb B. CasX enzymes comprise a distinct family of RNA-guided genome editors. Nature 2019; 566(7743): 218.

12. Harrington LB, Burstein D, Chen JS, Paez-Espino D, Ma E, Witte IP, Doudna JA. Programmed DNA destruction by miniature CRISPRCas14 enzymes. Sci 2018; 362(6416): 839-42.

13. Li SY, Cheng QX, Liu JK, Nie XQ, Zhao GP, Wang J. CRISPR-Cas12a has both cis-and trans-cleavage activities on single-stranded DNA. Cell Res 2018; 28(4): 491.

14. Komor AC, Kim YB, Packer MS, Zuris JA, Liu DR. Programmable editing of a target base in genomic DNA without doublestranded DNA cleavage. Nature 2016; 533:420-24.

15. Gaudelli NM, Komor AC, Rees HA, Packer MS, Badran AH, Bryson DI, Liu DR. Programmable base editing of $A{ }^{*} T$ to $G{ }^{*} C$ in genomic DNA without DNA cleavage. Nature 2017; 551:464-71.

16. Maeder ML, Linder SJ, Cascio VM, Fu Y, Ho QH, Joung JK. CRISPR RNA-guided activation of endogenous human genes. Nat Methods 2013; 10(10): 977.
17. Gilbert LA, Larson MH, Morsut L, Liu Z, Brar GA, Torres SE, Lim WA. CRISPR-mediated modular RNA-guided regulation of transcription in eukaryotes. Cell 2013; 154(2): 442-51.

18. McDonald JI, Celik H, Rois LE, Fishberger G, Fowler T, Rees R,Challen GA. Reprogrammable CRISPR/Cas9-based system for inducing site-specific DNA methylation. Biol Open 2016; 5(6): 866-74.

19. Cox DB, Gootenberg JS, Abudayyeh OO, Franklin B, Kellner MJ, Joung J, Zhang F. RNA editing with CRISPR-Cas13. Sci 358(6366), 2017; 1019-27.

20. Chen S, Lee B, Lee AYF, Modzelewski AJ, He L. Highly efficient mouse genome editing by CRISPR ribonucleoprotein electroporation of zygotes. J Biol Chem 2016; 291(28): 14457-67.

21. Fakhiri J, NickI M,Grimm D. Rapid and Simple Screening of CRISPR Guide RNAs (gRNAs) in Cultured Cells Using Adeno-Associated Viral (AAV) Vectors. In CRISPR Gene Editing, 2019; (pp. 111-126). Humana Press, New York, NY.

22. Malcolm T, Khalili K. U.S. Patent Application, 2018; No. 15/873,483.

23. Ali Z, Abul-Faraj A, Li L, Ghosh N, Piatek M, Mahjoub A, DineshKumar S. Efficient virus-mediated genome editing in plants using the CRISPR/Cas9 system. Mol Plant 2015; 8(8): 1288-91.

24. Li L, Hu S, Chen X. Non-viral delivery systems for CRISPR/Cas9-based genome editing: Challenges and opportunities. Biomaterials 2018; 171: 207-18.

25. Veillet F, Perrot L, Chauvin L, Kermarrec MP, Guyon-Debast A, Chauvin JE, Mazier M. Transgene-Free Genome Editing in Tomato and Potato Plants Using Agrobacterium-Mediated Delivery of a CRISPR/Cas9 Cytidine Base Editor. Int J Mo. Sci 2019; 20(2): 402.

26. Nekrasov V, Wang C, Win J, Lanz C, Weigel D, Kamoun S. Rapid generation of a transgene-free powdery mildew resistant tomato by genome deletion. Sci Rep 2017; 7(1): 482.

27. Woo JW, Kim J, Kwon SI, Corvalán C, Cho SW, Kim H, Kim JS. DNAfree genome editing in plants with preassembled CRISPR-Cas9 ribonucleoproteins. Nat Biotechnol 2015; 33(11): 1162.

28. Liang Z, Zhang K, Chen K, Gao C. Targeted mutagenesis in Zea mays using TALENs and the CRISPR/Cas system. J Genet Genomics 2014; 41(2): 63-68.

29. Bondy-Denomy J, Garcia B, Strum S, Du M, Rollins MF, HidalgoReyes Y, Davidson AR, Multiple mechanisms for CRISPR-Cas inhibition by anti-CRISPR proteins. Nature 2015; 526(7571): 136.

30. Wu Y, Liang D, Wang Y, Bai M, Tang W, Bao S, Yan Z, Li D, Li J. Correction of a Genetic Disease in Mouse via Use of CRISPRCas9. Cell Stem Cell 2013;13:659-62.

31. Long C, McAnally JR, Shelton JM, Mireault AA, Bassel-Duby R, Olson EN. Prevention of muscular dystrophy in mice by CRISPRCas9-mediated editing of germline DNA. Sci 2014;345:1184-88.

32. Maji B, Gangopadhyay SA, Lee M, Shi M, Wu P, Heler R, Mok B, Lim $D$, Siriwardena SU, Paul B, Dančík V. A high-throughput platform to identify small-molecule inhibitors of CRISPR-Cas9. Cell 2019;177(4): 1067-79.

33. Liu JJ, Orlova N, Oakes BL, Ma E, Spinner HB, Baney KL, Chuck J, Tan D, Knott GJ, Harrington LB, Al-Shayeb B. CasX enzymes comprise a distinct family of RNA-guided genome editors. Nature 2019; 566(7743): 218.

34. Technology Review, 2019, http://www.technologyreview.com. Last accessed June 3, 2019.

35. Thakore PI, Black JB, Hilton IB, Gersbach CA. Editing the epigenome: technologies for programmable transcription and epigenetic modulation. Nat Methods 2016; 13: 127-37.

36. Klann TS. CRISPR-Cas9 epigenome editing enables highthroughput screening for functional regulatory elements in the human genome. Nat Biotechnol 2017; 35: 561-68. 
37. Simeonov DR. Discovery of stimulation-responsive immune enhancers with CRISPR activation. Nature 2017: 549:111-5.

38. Liu SJ, CRISPRi-based genome-scale identification of functional long noncoding RNA loci in human cells. Sci 2017; aah7111.

39. Fujita T, Fujii H. Efficient isolation of specific genomic regions and identification of associated proteins by engineered DNA-binding molecule-mediated chromatin immunoprecipitation (enChIP) using CRISPR. Biochem Biophys Res Commun 2013; 439: 132-36.

40. Fujita T, Fuji H. Identification of proteins associated with an IFNYresponsive promoter by a retroviral expression system for enChIP using CRISPR. PLOS ONE 9 2014; e103084.

41. Sanjana NE. Genome-scale CRISPR pooled screens. Anal Biochem 2017; 532: 95-99.

42. Shalem O, Sanjana NE, Zhang F. High-throughput functional genomics using CRISPR-Cas9. Nat Rev Genet 2015;16: 299-311.

43. Shi J, Wang E, Milazzo JP, Wang Z, Kinney JB, Vakoc CR. Discovery of cancer drug targets by CRISPR-Cas9 screening of protein domains. Nat Biotech 2015;33: 661-67.

44. Chen Y, Zhang Y. Application of the CRISPR/Cas9 system to drug resistance in breast cancer. Adv Sci 2018; 5:1700964.

45. Parnas O, Jovanovic M, Eisenhaure Thomas M, Herbst Rebecca $H$, Dixit A, Ye Chun J, Przybylski D, Platt Randall J, Tirosh I, Sanjana Neville $E$, et al. A genome-wide crispr screen in primary immune cells to dissect regulatory networks. Cell 2015;162:675-86.

46. Zhou Y, Zhu S, Cai C, Yuan P, Li C, Huang Y, Wei W. High-throughput screening of a CRISPR-Cas9 library for functional genomics in human cells. Nature 2014;509:487-91.

47. Kiani S, Chavez A, Tuttle M, Hall RN, Chari R, Ter-Ovanesyan D, Qian J, Pruitt BW, Beal J, Vora S, et al. Cas9 gRNA engineering for genome editing, activation and repression. Nat Methods 2015;12:1051-54.

48. Sun Y, Jiao G, Liu Z, Zhang X, Li J, Guo X, Xia L. Generation of highamylose rice through CRISPR/Cas9-mediated targeted mutagenesis of starch branching enzymes. Front Plant Sci 2017; 8: 298.

49. Rodríguez-Leal D, Lemmon ZH, Man J, Bartlett ME, Lippman ZB. Engineering quantitative trait variation for crop improvement by genome editing. Cell 2017; 171(2): 470-80.

50. Soyk S, Müller NA, Park SJ, Schmalenbach I, Jiang K, Hayama R, Lippman ZB. Variation in the flowering gene SELF PRUNING 5 G promotes dayneutrality and early yield in tomato. Nat Genet 2017; 49(1): 162.

51. Hu B, Li D, Liu X, Qi J, Gao D, Zhao S, Yang L. Engineering non-transgenic gynoecious cucumber using an improved transformation protocol and optimized CRISPR/Cas9 system. Mol Plant 2017; 10(12): 1575-78.

52. Okuzaki A, Ogawa T, Koizuka C, Kaneko K, Inaba M, Imamura J, Koizuka N. CRISPR/Cas9-mediated genome editing of the fatty acid desaturase 2 gene in Brassica napus. Plant Physiol Biochem 2018; 131: 63-69.

53. Li J, Meng X, Zong Y, Chen K, Zhang H, Liu J, Gao C. Gene replacements and insertions in rice by intron targeting using CRISPR-Cas9. Nat Plants 2016; 2(10): 16139.

54. Shimatani Z, Ariizumi T, Fujikura U, Kondo A, Ezura H, Nishida K. Targeted base editing with crispr-deaminase in tomato. In plant genome editing with crispr systems. Humana Press, New York 2019; 297-307.

55. Peng A, Chen S, Lei T, Xu L, He Y, Wu L, Yao L, Zou X. Engineering canker-resistant plants through CRISPR/Cas9-targeted editing of the susceptibility gene CS LOB 1 promoter in citrus. Plant Biotechnol J 2017; 15(12): 1509-19.

56. Zhang A, Liu Y, Wang F, Li T, Chen Z, Kong D, Bi J, Zhang F, Luo X, Wang J, Tang J, Yu X, Liu G, Luo L. Enhanced rice salinity tolerance via CRISPR/Cas9-targeted mutagenesis of the OsRR22 gene. Mol Breeding 2019; 39(3): 47.
57. Paixão JFR, Gillet FX, Ribeiro TP, Bournaud C, Lourenço-Tessutti IT, Noriega DD, Grossi-de-Sa MF. Improved drought stress tolerance in Arabidopsis by CRISPR/dCas9 fusion with a Histone AcetylTransferase. Sci Rep 2019; 9(1): 8080.

58. McGill M. Plant Genome Editing Using CRISPR/Cas9: Investigating the role of ten 1 in the maintenance and protection of telomeres in Arabidopsis thaliana 2019; Celebrating Scholarship and Creativity Day. 60.

59. Zhao P, You Q, Lei MA. CRISPR/Cas9 deletion into the phosphate transporter SIPHO1; 1 reveals its role in phosphate nutrition of tomato seedlings. Physiol Plant 2018.

60. Veillet F, Perrot L, Chauvin L, Kermarrec MP, Guyon-Debast A, Chauvin JE, Mazier M. Transgene-free genome editing in tomato and potato plants using agrobacterium-mediated delivery of a CRISPR/Cas9 cytidine base editor. Int J Mol Sci 2019; 20(2): 402.

61. Zsögön A, Čermák T, Naves ER, Notini MM, Edel KH, Weinl S, Peres LEP. De novo domestication of wild tomato using genome editing. Nature Biotechnol 2018; 36: 1211-16.

62. Calyxt, First commercial sale of calyxt high oleic soybean oil on the U.S. market, Press Release, 2019.

63. Jiang Y, Chen B, Duan C, Sun B, Yang J, Yang S. Multigene editing in the Escherichia coli genome via the CRISPR-Cas9 system. Appl Environ Microbiol 2015; 81(7): 2506-14.

64. Wang Y, Zhang ZT, Seo SO, Lynn P, Lu T, Jin YS, Blaschek HP. Gene transcription repression in Clostridium beijerinckii using CRISPRdCas9. Biotechnol Bioeng 2016 113(12): 2739-43.

65. Zhu DK, Yang XQ, He Y, Zhou WS, Song XH, Wang JB, Zhang Y, Liu MF, Wang MS, Jia RY, Chen S, Sun KF, Yang Q, Wu Y, Chen XY, Cheng AC. Comparative genomic analysis identifies structural features of CRISPR-Cas systems in Riemerella anatipestifer. BMC genomics 2016; 17(1): 689.

66. Song $X$, Huang $H$, Xiong Z, Ai L, Yang S. CRISPR-Cas9D10A nickaseassisted genome editing in Lactobacillus casei. Appl Environ Microbiol 2017 83(22): e01259-17.

67. Aparicio T, de Lorenzo V, Martínez-García E. CRISPR/Cas9based counter selection boosts recombineering efficiency in Pseudomonas putida. Biotechnol J 2018; 13(5): 1700161.

68. Medina-Aparicio L, Dávila S, Rebollar-Flores JE, Calva E, HernándezLucas I. The CRISPR-Cas system in Enterobacteriaceae. Pathogens and disease 2018; 76(1): fty002.

69. Li K, Cai D, Wang Z, He Z, Chen S. Development of an efficient genome editing tool in Bacillus licheniformis using CRISPR-Cas9 nickase. Appl Environ Microbiol 2018; 84(6): e02608-17.

70. Xiao Y, Wang S, Rommelfanger S, Balassy A, Barba-Ostria C, Gu P, Galazka JM, Zhang F. Developing a Cas9-based tool to engineer native plasmids in Synechocystis sp. PCC 6803. Biotechnol Bioeng 2018; 115(9): 2305-14.

71. Li L, Wei K, Zheng G, Liu X, Chen S, Jiang W, Lu Y. CRISPR-Cpf1assisted multiplex genome editing and transcriptional repression in Streptomyces. Appl Environ Microbiol 2018 84(18): e00827-18.

72. Wang Y, Liu Y, Liu J, Guo Y, Fan L, Ni X, Zhang X, Wang M, Zheng $P$, Sun J, Ma Y. MACBETH: multiplex automated Corynebacterium glutamicum base editing method. Metab Eng 2018; 47:200-10.

73. Shariat N. The combination of CRISPR-MVLST and PFGE provides increased discriminatory power for differentiating human clinical isolates of Salmonella enterica subsp. enterica serovar Enteritidis. Food Microbiol 2013; 34: 164-73.

74. Barrangou R. Genomic impact of CRISPR immunization against bacteriophages. Biochem Soc Trans 2013; 41: 1383-91.

75. Barrangou R, Horvath P. CRISPR: new horizons in phage resistance and strain identification. Annu Rev Food Sci Technol 2013; 3: 143-62. 
76. Gomaa AA. Programmable removal of bacterial strains by use of genome-targeting CRISPR-Cas systems. MBio 2014; 5: e00928e1013.

77. Bondy-Denomy J, and Davidson AR. To acquire or resist: the complex biological effects of CRISPR-Cas systems. Trends Microbiol 2014; 22: 218-25.

78. Martin-Laffon J, Kuntz $M$, Ricroch $A E$, inventors. Worldwide CRISPR patent landscape shows strong geographical biases. Nat Biotechnol 2019; 37(6):613-20.

79. Jinek M, Chylinski K, Fonfara I, Hauer M, Doudna JA, Charpentier E. A programmable dual-RNA-guided DNA endonuclease in adaptive bacterial immunity. Sci 2012; 337(6096): 816-21.

80. Swiech L, Heidenreich M, Banerjee A, Habib N, Li Y, Trombetta J, Zhang, F. In vivo interrogation of gene function in the mammalian brain using CRISPR-Cas9. Nature Biotechnol 2015; 33(1): 102.

81. Jacobi AM, Rettig GR, Turk R, Collingwood MA, Zeiner SA, Quadros RM, Gurumurthy CB. Simplified CRISPR tools for efficient genome editing and streamlined protocols for their delivery into mammalian cells and mouse zygotes. Methods 2017; 121: 16-28.

82. Amoasii L, Hildyard JC, Li H, Sanchez-Ortiz E, Mireault A, Caballero D, Bassel-Duby R. Gene editing restores dystrophin expression in a canine model of Duchenne muscular dystrophy. Sci 2018; 362(6410): 86-91.

83. Santiago-Fernández O, Osorio FG, Quesada V, Rodríguez F, Basso S, Maeso D, Freije JM. Development of a CRISPR/Cas9-based therapy for Hutchinson-Gilford progeria syndrome. Nat Med 2019; 1.

84. Ihry RJ, Worringer KA, Salick MR, Frias E, Ho D, Theriault K, Randhawa R. p53 inhibits CRISPR-Cas9 engineering in human pluripotent stem cells. Nat Med 2018; 24(7): 939.

85. Schaefer KA, Wu WH, Colgan DF, Tsang SH, Bassuk AG, Mahajan VB. Unexpected mutations after CRISPR-Cas9 editing in vivo. Nat Met 2017;14(6): 547.

86. Beaumont KA, Shekar SN, Cook AL, Duffy DL, Sturm RA. Red hair is the null phenotype of MC1R. Hum Mutat 2008; 29(8): E88-E94.

87. Deng S, Kongpan LI, Wang F, Ning LI, Liu G, Zhao Y, Lian Z. One-step generation of myostatin gene knockout sheep via the CRISPR/ Cas9 system 2014; 1: 2-5.
88. Lu Y, Xue J, Deng T, Zhou X, Yu K, Huang M, Gong Y. A phase I trial of PD-1 deficient engineered T cells with CRISPR/Cas9 in patients with advanced non-small cell lung cancer. 2018.

89. June $\mathrm{CH}, \mathrm{O}^{\prime}$ Connor RS, Kawalekar OU, Ghassemi S, Milone MC. CAR T cell immunotherapy for human cancer. Sci 2018; 359(6382): 1361-65.

90. Normile D. Shock greets claim of CRISPR-edited babies 2018.

91. Wei $X$, Nielsen R. CCR5- $\triangle 32$ is deleterious in the homozygous state in humans. Nat Med 2019; 1.

92. OGTR, Office of the Gene Technology Regulator, Questions $\&$ answers on the technical review of the gene technology regulations 2001 (10 April 2019).

93. World Trade Organization (WTO) Committee on Sanitary and Phytosanitary Measures, International Statement on Agricultural Applications of Precision Biotechnology (Oct. 30, 2018).

94. Eriksson D, Kershen D, Nepomuceno A, Pogson BJ, Prieto $H$, Purnhagen $K$, Whelan A. A comparison of the EU regulatory approach to directed mutagenesis with that of other jurisdictions, consequences for international trade and potential steps forward. New Phytol 2019; 222(4): 1673-84.

95. Dobrovidova O. Russia joins in global gene-editing bonanza. Nature 2018; 569(7756): 319.

96. NHK World-Japan. 2018.Govt. Panel to not regulate some genome editing. [WWW document] URL https://www3.nhk.or.jp/nhkworld/ en/news/20180821_14/ [accessed 21 August 2018].

97. Callaway E. CRISPR plants now subject to tough GM laws in European Union 2018; Nature 560(7716):16.

98. Kupferschmidt K. EU verdict on CRISPR crops dismays scientists 2018.

99. Euractive. The EU future of new plant breeding techniques, Special Report May 2019 http://eurac.tv/9qiu

100. Jeggo PA. Identification of genes involved in repair of DNA doublestrand breaks in mammalian cells. Radiat Res 1998; 150(5s): s80-S91. 